\title{
Spatial pattern changes of biomass, litterfall and coverage with environmental factors across temperate grassland subjected to various management practices
}

\author{
Miao Liu $\cdot$ Guohua Liu $\cdot$ Xiaoxuan Zheng
}

Received: 12 March 2014 / Accepted: 11 November 2014/Published online: 16 November 2014

(C) Springer Science+Business Media Dordrecht 2014

\begin{abstract}
Introduction Understanding the influences of different utilization patterns in different grassland types on grassland traits is essential for grassland conservation and improvement of grassland management. Grazing, mowing, and fencing have the potential to substantially affect vegetation characteristics. The general pattern and mechanisms for relationships between vegetation characteristics and abiotic factors are fundamental issues in ecology. The effect of the key factors on vegetation traits under different management practices has been rarely comprehensively elucidated in previous studies, especially across the temperate grasslands in the Hulunbuir region. Therefore, the principal purposes of this study were: (1) to analyze the effects of different management practices on vegetation characteristics using data investigated from 23 sites across the temperate grasslands; (2) to explore the relationship of environmental factors with
\end{abstract}

M. Liu · G. Liu $(\bowtie) \cdot X$. Zheng

State Key Laboratory of Urban and Regional Ecology,

Research Center for Eco-environmental Sciences, Chinese

Academy of Sciences, Beijing 100085, China

e-mail: ghliu@rcees.ac.cn

M. Liu

e-mail: liumiaoerdos@163.com

M. Liu

University of Chinese Academy of Sciences,

Beijing 100049, China vegetation dynamics, and to identify the main factors using correlation analysis; and (3) to predict the evolution of vegetation dynamics with the major factors using the generalized additive modelat the landscape scale.

Materials and methods The study area is situated at the western part of Mt. Daxing'anling, Hulunbuir, Inner Mongolia, China. Samples were collected in the grasslands utilized for grazing (always from 10 sampled sites), mowing (since 2003, from 6 sampled sites), and fencing (since 2003, from 7 samples sites). In each site, we investigated above ground biomass, below ground, litter, coverage and soil properties in five plots $(1 \mathrm{~m} \times 1 \mathrm{~m})$ at a $10 \mathrm{~m}$ interval along a transect. Data pertaining to the environmental factors and vegetation characteristics in different utilization types were compared using ANOVA. The relationship of the main elements with vegetation traits was analyzed using CA in these utilization types. GAM analysis was conducted to explore the evolutionary trend of vegetation dynamics with respect to the critical factors at the landscape scale.

Conclusion Fencing and mowing practices, which can improve vegetation traits, and increase grassland carbon sink, should be continued to promote the Hulunbuir grasslands, rather than grazing management. Thus, appropriate reforms concerning the proper utilize the grassland (e.g. mowing and fencing) is necessary to ensure sustainability of the grassland ecological system, and what is more, the effects of the ecological project in the sustainable development of 
the temperate grasslands in the Hulunbuir region should be gradually explored.

Keywords Plant biomass - Litterfall - Coverage · Grassland management practices · Landscape scale

\section{Introduction}

Grasslands account for $25 \%$ of the land surface of the earth and $10 \%$ of global carbon stocks, and have an important function in global carbon cycling (Scurlock et al. 2002; Hui and Jackson 2006). Chinese grasslands are generally distributed in three different regions: temperate grasslands on the Inner Mongolian Plateau, alpine grasslands on the Tibetan Plateau, and mountain grasslands in the Xinjiang mountain areas (Geng et al. 2012). The Hulunbuir grasslands contain large tracts of grass that make this area appropriate for research on different ecological styles, and $80 \%$ of its area is covered by natural temperate grassland. However, the Hulunbuir grasslands have faced environmental degradation in recent years because of intensified human activities in the area, such as overgrazing and intensive wood harvesting ( $\mathrm{Li}$ et al. 2007; Waldron et al. 2010). These activities have resulted in sensitive changes in the vegetation characteristics of the region. Understanding the influences of different utilization patterns in different grassland types on grassland traits is essential for grassland conservation and improvement of grassland management (Yang et al. 2012). Grazing, mowing, and fencing have the potential to substantially affect vegetation characteristics (Zheng et al. 2012). The general pattern and mechanisms for relationships between vegetation characteristics and abiotic factors are fundamental issues in ecology (Schulze and Mooney 1993).

The effects of precipitation or temperature, different land utilization types, and human disturbance (Redmann et al. 1993; Sun et al. 2013a, b) on soil texture, biodiversity, or biomass were conducted in various grassland ecosystems. Biomass of perennial grasses, perennial forbs, and annual forbs is greater at exclusion sites than at grazed sites. Meanwhile, the overall grazing exclosure site improves the vegetation composition and soil quality in the Imam Kandi Rangelands (Mofidi et al. 2013). However, grazing increases the temperature sensitivity of organic matter decomposition in the soils of temperate grasslands (Paz-Ferreiro et al. 2012). Additionally, grazing depressed vegetation biomass and community composition in a Tibetan alpine meadow (Sun et al. 2011). Interestingly, some reports hold that grazing is a more suitable management practice in maintaining high biodiversity than mowing is (Weiss et al. 2013), and seasonal grazing can enrich vegetation biomass (Whitford and Steinberger 2012).

All of these results are explainable by several hypotheses, such as the functional equilibrium hypothesis, which adequately predicts the impact of environmental factors on biomass allocation among dissimilar organs competing for nutrients and water to achieve maximal growth velocity (Yang et al. 2009). Another hypothesis is the grazing optimization hypothesis, which states that productivity should be maximized at light to moderate levels of grazing, which can increase photosynthetic rates and promote the primary production of grasslands (Luo et al. 2012). Moreover, a potentially important organizing principle in grazing systems is belowground biomass (BGB) transfers to the surface layer and allocates more biomass to the surface layer, rather than to the subsurface of soil exposed to the gradients of grazing pressure (Burke et al. 1999).

The relationship of BGB and aboveground biomass (AGB), litter, and coverage to the various environmental factors of different utilization patterns has been frequently debated, particularly in the context of temperate grasslands, even though these key environmental factors have been frequently studied. However, the effect of the key factors on vegetation traits (i.e., AGB, BGB, litter, and coverage) under different management practices has been rarely comprehensively elucidated in previous studies, especially across the temperate grasslands in the Hulunbuir region. Therefore, the principal purposes of this study were: (1) to analyze the effects of different management practices on vegetation characteristics (i.e., AGB, $\mathrm{BGB}$, litter, and coverage) using data investigated from 23 sites across the temperate grasslands; (2) to explore the relationship of environmental factors with vegetation dynamics, and to identify the main factors using correlation analysis (CA); and (3) to predict the evolution of vegetation dynamics with the major factors using the generalized additive model (GAM) at the landscape scale. 
Fig. 1 Spatial distribution of the sampling sites. Little black circles, gray solid circles, and big black circles represent sampling sites of mowing, grazing, and fencing management practices, respectively. Numerous points overlap each other and are not visible

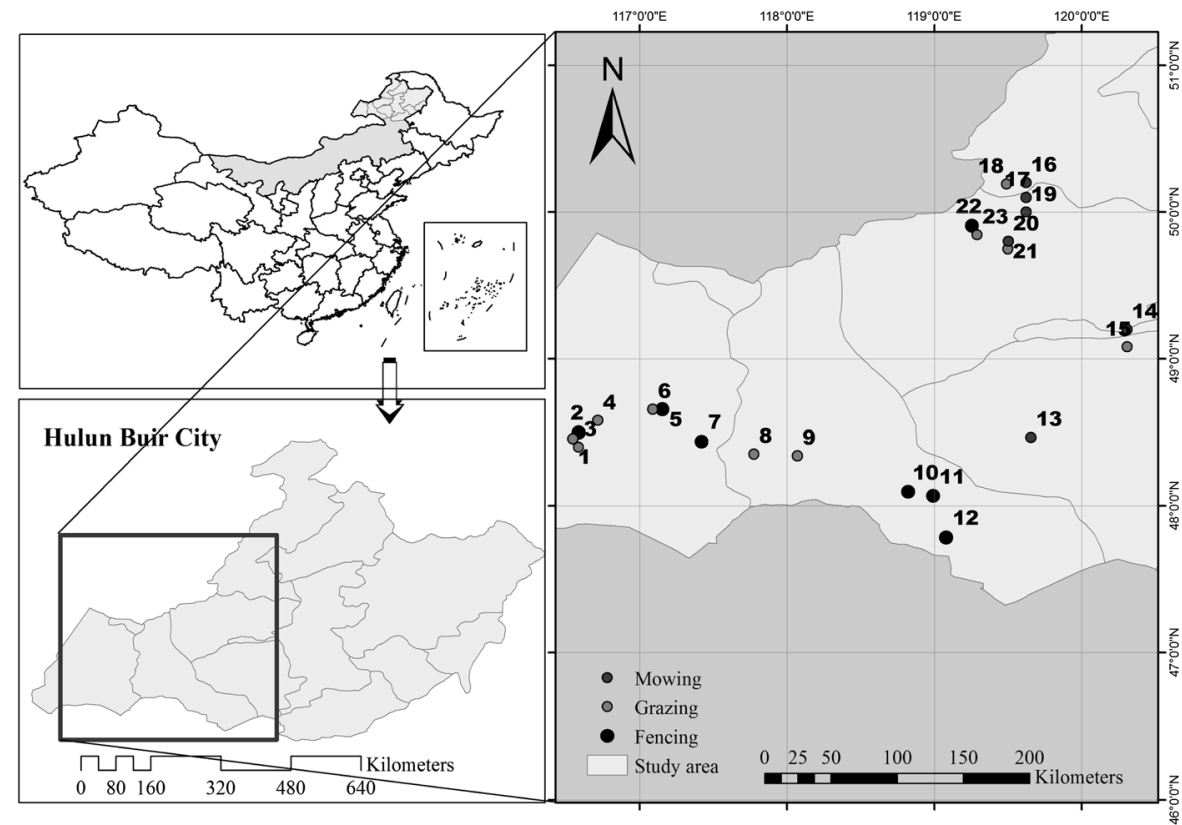

\section{Materials and methods}

Study area

The study area is situated at the western part of Mt. Daxing'anling, Hulunbuir, Inner Mongolia, China (Fig. $1 ; 115^{\circ} 31^{\prime}-126^{\circ} 04^{\prime} \mathrm{E}, 47^{\circ} 05^{\prime}-53^{\circ} 20^{\prime} \mathrm{N}$ ). The study area has a mean annual precipitation and temperature of $339 \mathrm{~mm}$ and $2.2{ }^{\circ} \mathrm{C}$, respectively (Liu et al. 2010; Zheng et al. 2010). The orographic features were relatively unchanged in the area, and the maximal difference in elevation was no more than $50 \mathrm{~m}$. Chernozem and chestnut soil are the main soil types (Liu et al. 2008).

Data collection and sample analysis

The database required for this study included information pertaining to environmental factors [i.e., precipitation, temperature, soil nitrogen $(\mathrm{TN})$, soil organic carbon (TOC), soil phosphorous (TP), available phosphorous (AP), bulk density (BD), soil water content (SWC)], and vegetation characteristics (i.e., AGB, BGB, litter, and coverage). In 2006, sites were surveyed crossing the Hulunbuir grasslands from west to east and from south to north during the vegetation growth period (June, July, and August). Samples were collected in the grasslands utilized for grazing (always from 10 sampled sites), mowing (since 2003, from 6 sampled sites), and fencing (since 2003, from 7 samples sites) (Fig. 1). In each site, we investigated AGB, BGB, litter, and coverage in five plots $(1 \mathrm{~m} \times 1 \mathrm{~m})$ with similar topography and solar status at a $10 \mathrm{~m}$ interval along a transect. AGB was determined by mowing the plants at ground level and drying samples in an oven at $65{ }^{\circ} \mathrm{C}$ until a constant weight was obtained. BGB was collected from soil depths of 0 to $15 \mathrm{~cm}$ and 15 to $30 \mathrm{~cm}$, where the majority of BGB biomass is located (Li et al. 2011). Root samples were obtained from blocks using $5 \mathrm{~cm}$ diameter soil cores, soaked in water to remove the residual soil using a $0.5 \mathrm{~mm}$ sieve, and dried at $65{ }^{\circ} \mathrm{C}$ to a constant weight. Litter was collected, cleaned by removing impurities, and oven-dried at $65^{\circ} \mathrm{C}$ until a constant weight was obtained. Coverage was measured by visual estimation. Soil samples were collected from five replicate soil profiles to determine soil properties at $30 \mathrm{~cm}$ soil depth. After being air-dried and sieved ( $2 \mathrm{~mm}$ mesh), the soil samples were carefully handpicked to extract the surface organic materials and fine roots for soil chemical property analysis. Each mixed soil sample was divided into two parts. One subsample was oven-dried at $105{ }^{\circ} \mathrm{C}$ to a constant weight to measure SWC and BD gravimetrically. The other subsample was ground in a ball mill for TOC, TN, TP, and AP analyses. Soil properties 
were determined following all standard protocols (Bao 2000).

\section{Data analysis}

Data pertaining to the environmental factors and vegetation characteristics in different utilization types were compared using ANOVA. CA, which can identify the major variables that significantly influence the response variables, was used to examine the relationship of vegetation characteristics with environmental factors to identify the main influencing variables on vegetation dynamics from all samples. The relationship of the main elements with vegetation traits was analyzed using CA in these utilization types. GAM analysis was conducted to explore the evolutionary trend of vegetation dynamics with respect to the critical factors at the landscape scale. In this study, all statistical analyses and plotting were performed using the R-freedom software (version 2.15) ( $\mathrm{R}$ Development Core Team 2011).
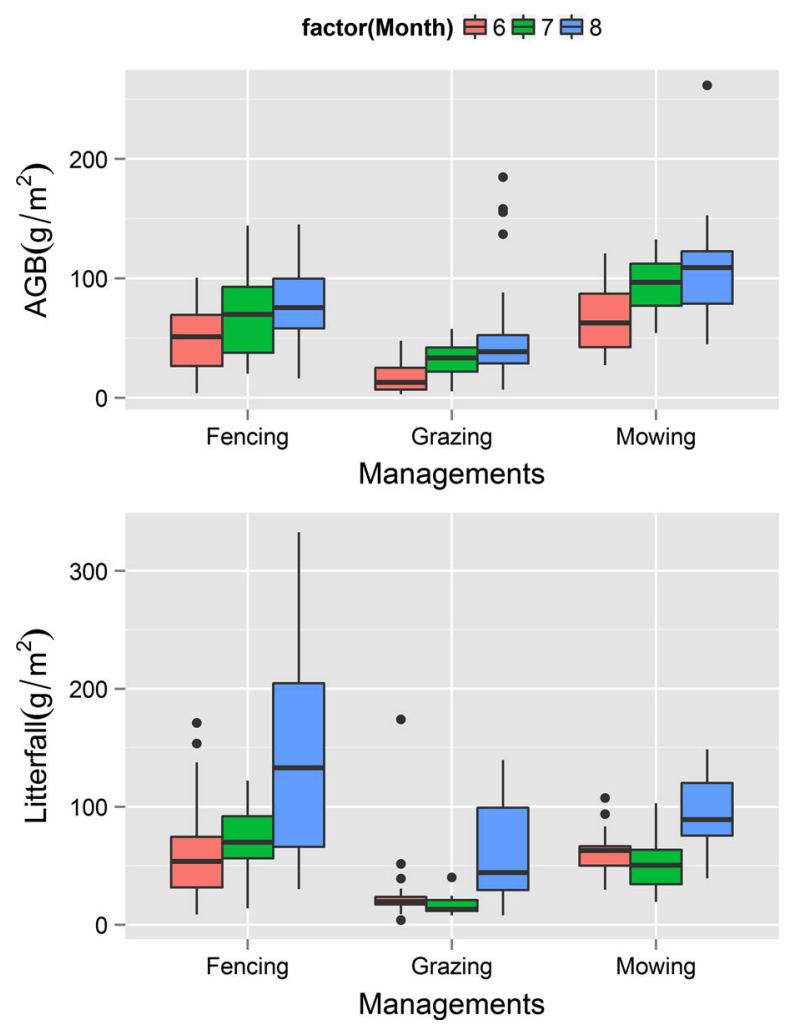
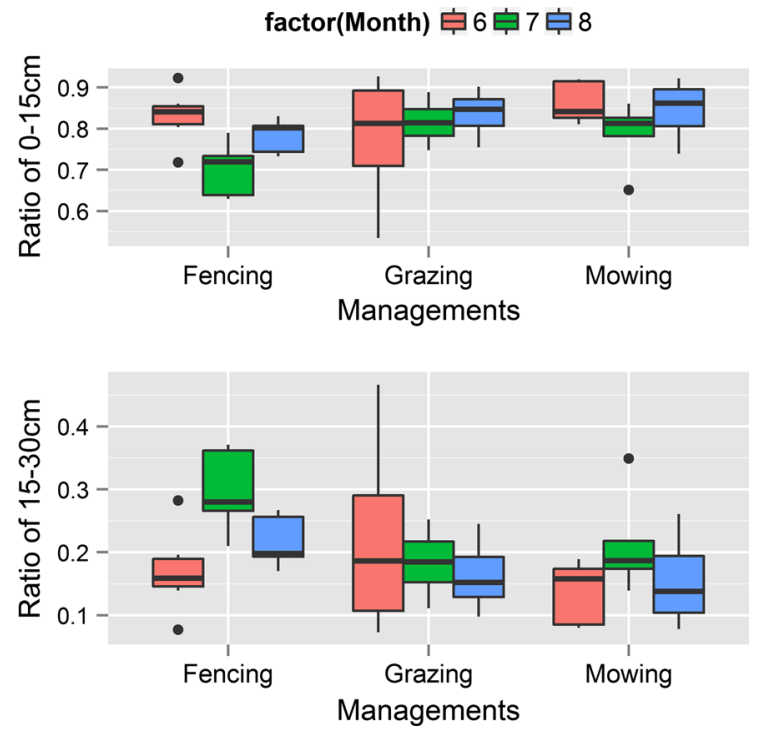

Fig. 3 Percentages of $0-15$ and $15-30 \mathrm{~cm}$ of BGB in June (red bar), July (green bar), and August (blue bar) of grazing compared with those of mowing and fencing grassland management practices
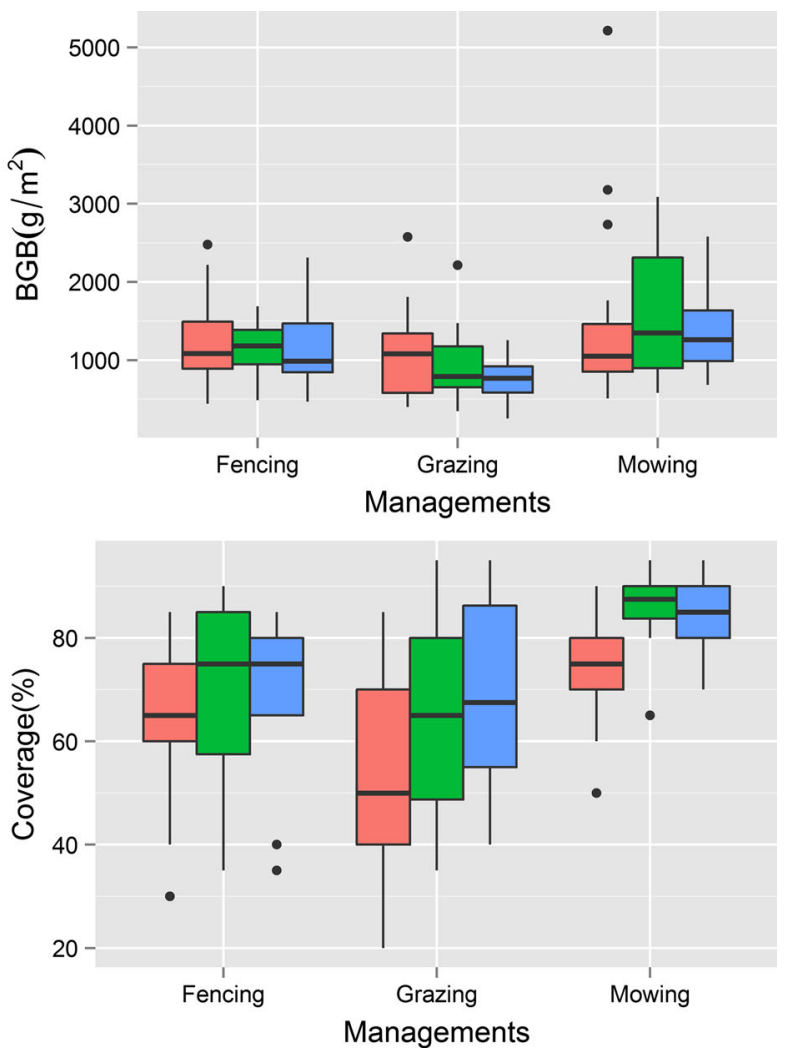

Fig. 2 Vegetation characteristics (i.e., AGB, BGB, litter, and coverage) in June (red bar), July (green bar), and August (blue bar) of grazing compared with those of mowing and fencing grassland management practices 


\section{Results}

Vegetation characteristics under different grassland management practices

Aboveground biomass, BGB, litter, and coverage varied markedly during the entire growth period of plants across different utilization types (Fig. 2). The maximum values of AGB (261.6 $\left.\mathrm{g} \mathrm{m}^{-2}\right)$, BGB $\left(5,212.7 \mathrm{~g} \mathrm{~m}^{-2}\right)$, and coverage $(95 \%)$ all appeared in mowing management (August, June and July), whereas that of litter was found in fencing management in June (332.6 $\mathrm{g} \mathrm{m}^{-2}$ ). Moreover, the AGB of all management practices increased from June to August. The minimum values of coverage $(50 \%)$ and AGB $\left(2.9 \mathrm{~g} \mathrm{~m}^{-2}\right)$ were observed in grazing management in July.

The ratio of $\mathrm{BGB}$ at soil depths of $0-15$ and $15-30 \mathrm{~cm}$ markedly changed throughout the entire growth period (Fig. 3). The overall tendency of BGB was higher at the top layer than that at the subsurface layer. The minimum (7.3\%) and maximum (92.7 \%) values at the top and subsurface layers, respectively, emerged in fencing management in June.
A significant difference was observed among different management practices for vegetation characteristics in June, July, and August. The results show that all of the biome factors significantly differed from one another, with the exception of AGB in June $(P=0.05)$. In addition, a significant difference in BGB in July at the top and subsurface layers was observed between fencing and mowing management practices. These variations were all significant at the 0.05 level. The remaining indicators included no significant differences among the various utilization types.

Relationship of vegetation characteristics with the main environmental factors under different grassland management practices

The positive correlations were observed between precipitation and AGB, BGB and coverage at the 0.05 level (Table 1), whereas a negative correlation was observed between litterfall and precipitation $\left(R^{2}=-0.245\right)$ for fencing grassland managements practices at the 0.05 or 0.01 levels. Interestingly, there are negative correlations between litterfall and

Table 1 Correlations between vegetation characteristics and environmental factors at different grassland management practices

\begin{tabular}{|c|c|c|c|c|c|c|c|c|c|c|}
\hline & Precipitation & Temperature & TOC & $\mathrm{TP}$ & AP & $\mathrm{TN}$ & BDT & SWCT & BDS & SWCS \\
\hline \multicolumn{11}{|l|}{ Fencing } \\
\hline AGB & $0.515^{* *}$ & $-0.448^{* *}$ & $0.268 * *$ & -0.108 & $-.400^{* *}$ & $0.298 * *$ & $-0.595^{* *}$ & $0.375^{*}$ & $-0.460 * *$ & $0.570 * *$ \\
\hline BGB & $0.276^{*}$ & $-0.297 *$ & 0.105 & -0.154 & $-0.327 * *$ & -0.045 & 0.233 & -0.171 & $0.414 * *$ & -0.076 \\
\hline Litterfall & $-0.245^{*}$ & $0.225^{*}$ & -0.184 & $-.240^{*}$ & 0.082 & -0.15 & 0.043 & -0.255 & 0.065 & -0.119 \\
\hline Coverage & $0.376 * *$ & $-0.218^{*}$ & 0.079 & -0.108 & $-0.287 * *$ & 0.138 & $-0.570 * *$ & $0.523 * *$ & $-0.527 * *$ & $0.578^{* *}$ \\
\hline \multicolumn{11}{|l|}{ Grazing } \\
\hline AGB & -0.167 & 0.14 & -0.051 & -0.05 & 0.151 & -0.079 & 0.116 & -0.136 & 0.007 & 0.000 \\
\hline BGB & 0.054 & -0.128 & 0.117 & -0.032 & 0.041 & 0.158 & -0.151 & 0.09 & 0.178 & -0.137 \\
\hline Litterfall & $-0.504 * *$ & 0.235 & -0.183 & -0.064 & 0.172 & -0.141 & 0.007 & -0.273 & -0.321 & 0.001 \\
\hline Coverage & $0.339 * *$ & $-0.244 * *$ & 0.031 & $-.234^{*}$ & $-.185^{*}$ & -0.073 & 0.096 & -0.051 & 0.214 & -0.117 \\
\hline \multicolumn{11}{|l|}{ Mowing } \\
\hline AGB & 0.229 & $-0.248^{*}$ & -0.05 & 0.199 & -0.148 & 0.088 & -0.135 & 0.027 & -0.125 & 0.163 \\
\hline BGB & 0.057 & -0.043 & -0.278 & -0.221 & -0.164 & $-0.321^{*}$ & 0.032 & 0.133 & -0.359 & -0.008 \\
\hline Litterfall & $0.333^{* *}$ & $-0.319 * *$ & $-0.235^{*}$ & -0.036 & -0.153 & $-0.307 * *$ & 0.166 & -0.150 & -0.100 & -0.159 \\
\hline Coverage & $0.332 * *$ & $-0.377^{* *}$ & -0.015 & $0.325^{* *}$ & $-0.337 * *$ & $0.258^{*}$ & 0.055 & -0.141 & -0.119 & 0.036 \\
\hline
\end{tabular}

$\mathrm{T}$ and $\mathrm{S}$ represented top soil layer $(0-15 \mathrm{~cm})$ and subsurface layer $(15-30 \mathrm{~cm})$

$A G B$ above-ground biomass, $B G B$ below-ground biomass, $T P$ total phosphorus, $T N$ total nitrogen, $T O C$ total organic carbon, $A P$ available phosphorus, $B D$ bulk density, $S W C$ Soil water content

** Correlation is significant at the 0.01 level, * Correlation is significant at the 0.05 level 
precipitation and between coverage and temperature, but a positive correlation was observed between precipitation and coverage $\left(R^{2}=0.339\right)$ for the grazing management practice. In the mowing management practice, we found that there were positive and negative relationships of litterfall with precipitation and temperature $\left(R^{2}=0.333,-0.319\right)$, respectively. Meanwhile, we also observed that there were positive and negative relationships of coverage with precipitation and temperature $\left(R^{2}=0.332,-0.377\right)$, respectively.

Correlation analyses revealed that AGB and soil properties were all significant with the exception of $\mathrm{TP}$, and AGB was positively related to the TOC, TN, SWCT and SWTS. There was also a significant correlation between coverage and soil physical properties (BDT, BDS, SWCT, and SWCS) studied for the fencing management practice. Additionally, there was a significant positive correlation between coverage and $\mathrm{TN}$ for mowing grassland managements practice,

Fig. 4 Predicted changes in vegetation characteristics (i.e., AGB, BGB, litter, and coverage) with the major environmental factors at fencing management practices. Rug plot on the $x$ axis represents the observed value, and the gray belts indicate the credible intervals
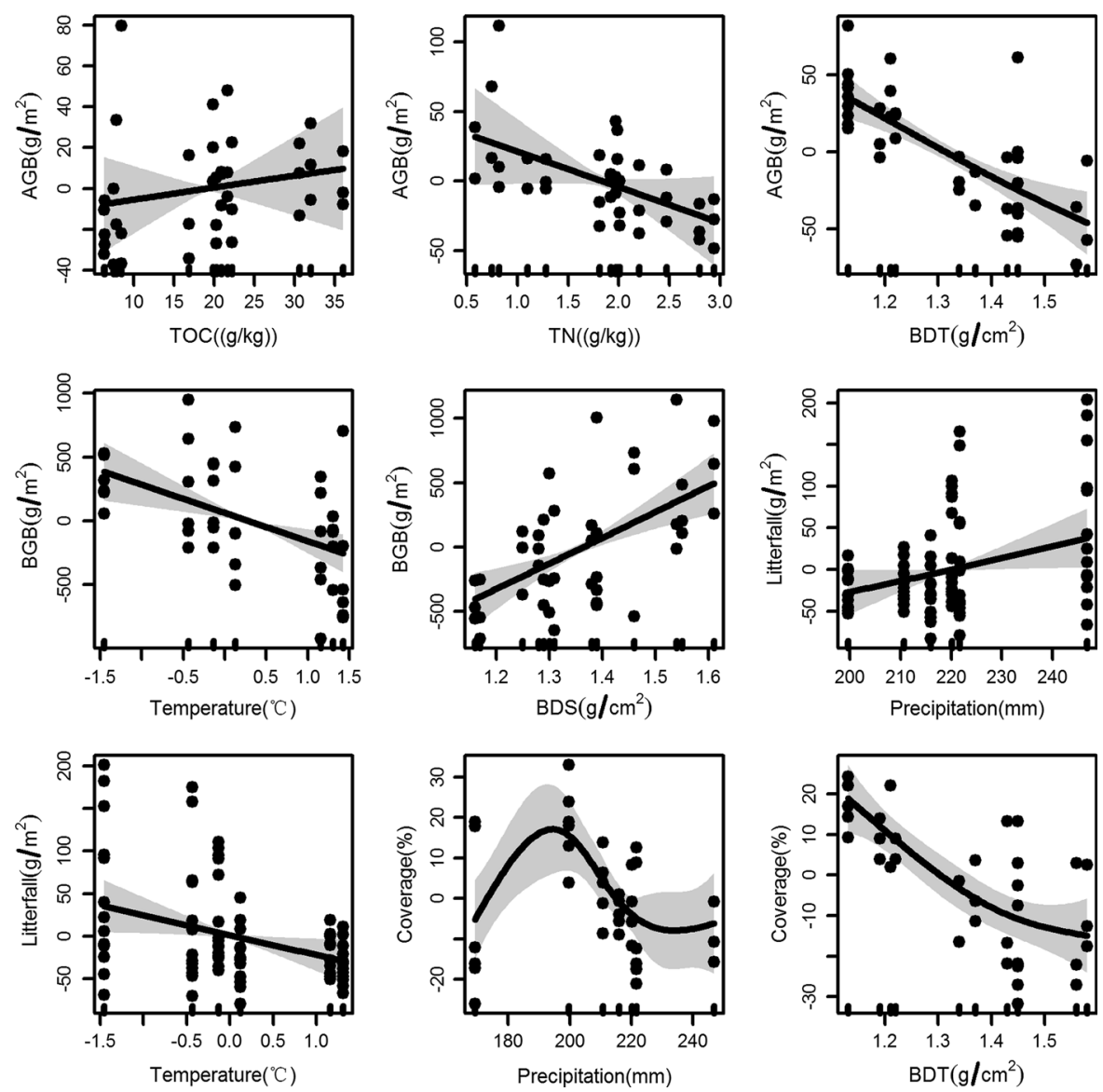

but different relationships were observed; TN had a positive effect on BGB and litterfall (Table 1).

Prediction of the changes in vegetation characteristics associated with the main environmental factors using GAM at the landscape scale

To further explore the evolutionary tendencies of vegetation characteristics in correlation with the main environmental factors, their relationships were analyzed using GAM. The results of GAM spline fittings relating each environmental factor to vegetation characteristics varied from simple linear functions to highly complex curves. The response curves of the critical factors for all samples in Hulunbuir are shown in Figs. 4, 5 and 6.

In Fig. 4 (for fencing grassland management practice), a linear increase in AGB was observed with increasing precipitation, but declining trends were observed with TN 

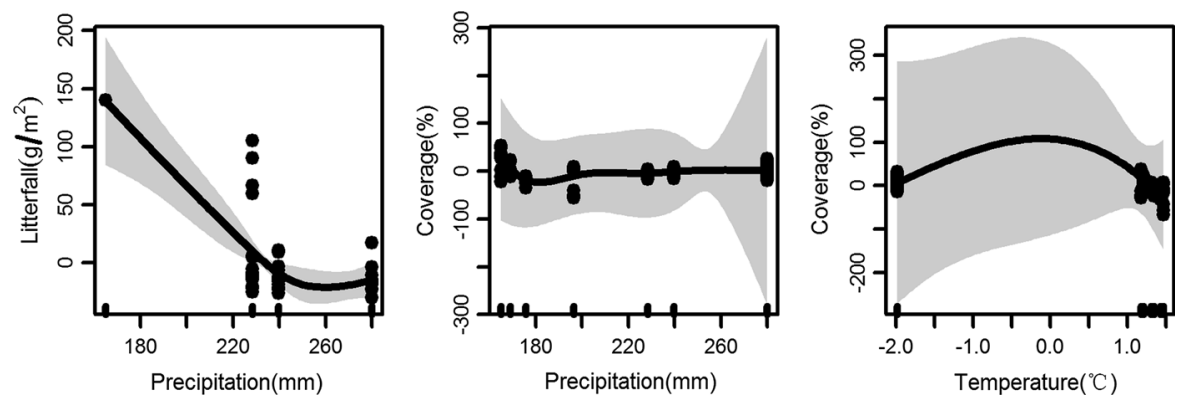

Fig. 5 Predicted changes in vegetation characteristics (i.e., AGB, BGB, litter, and coverage) with the major environmental factors at grazing grassland management practices. Rug plot on the $x$-axis represents the observed value, and the gray belts indicate the credible intervals
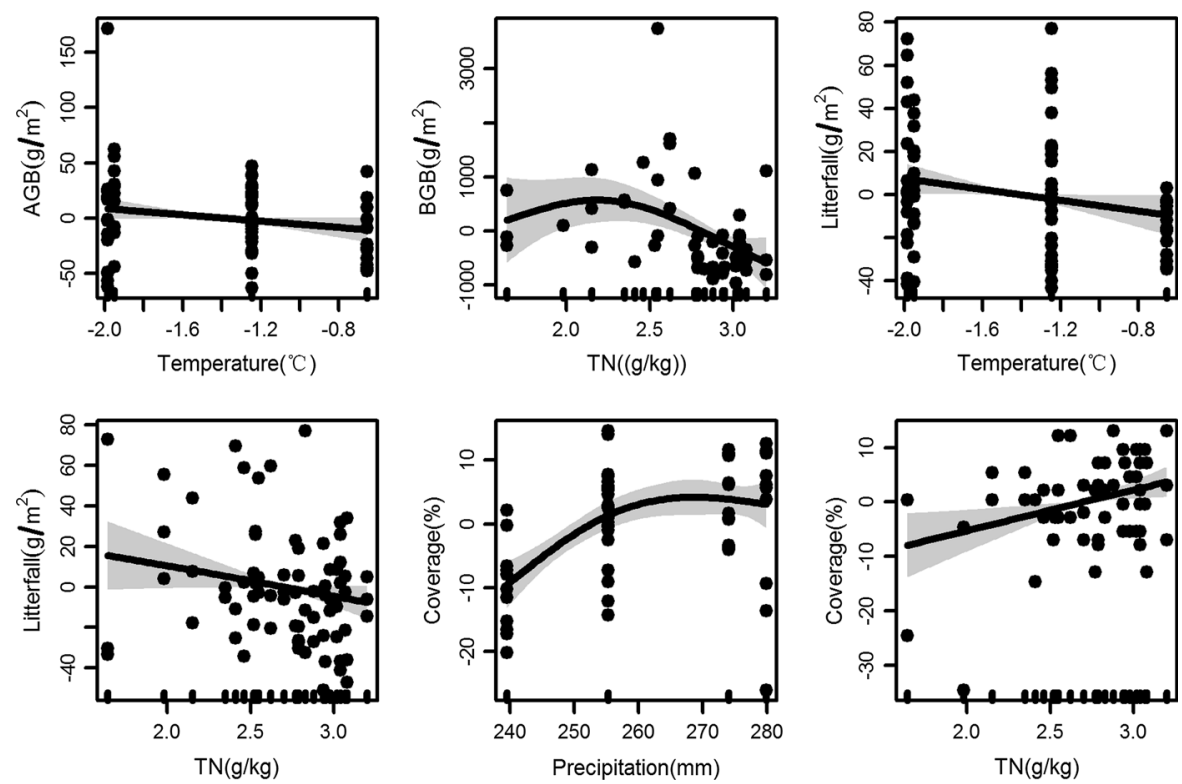

a linear decrease in litterfall with increasing soil TN were also observed. Increasing trends of coverage with precipitation and $\mathrm{TN}$ were observed. However, the relationships of the vegetation characteristics with other major abiotic factors were not apparent because of the discrete distribution of values. These relationships could not be explained using GAM.

\section{Discussion}

Vegetation dynamics in the context of different types of grassland utilization

Vegetation characteristics largely differed as a result of various management patterns. AGB, BGB, and 
coverage in August reached maximum values in all management practices, with respect to hydrothermal conditions. The vegetation characteristics in mowing management were higher than those in the other types of management, in agreement with the results of (Medina-Roldan et al. 2012), who documented that grassland production could be relatively decreased in grazed land because of the bitten effect caused by livestock. Litterfall in grazing management was distinctly lower than in grazing and mowing management, which may be due to the absence of human interference in the grassland ecosystem. Many similar studies in other areas also found that exclusion of livestock grazing is a simple and effective method for restoring vegetation productivity in degraded grasslands (Wu et al. 2009, 2010). More BGB was observed in the topsoil layer than that in the subsurface soil layer. This result suggests that roots were most distributed in the shallower layer, possibly because of physical barriers inhibiting root growth in un-grazed regions, such as bites from livestock, which result in faster root turnover. (Jackson et al. 1996) verified that $83 \%$ of BGB is distributed in the upper $30 \mathrm{~cm}$ of soil in temperate grasslands. The results confirmed that grasslands used for grazing in northern China can sequester carbon in soil under appropriate grazing pressure, similar to the mowing pattern, but they lose carbon under heavy grazing. Thus, appropriate grazer densities will promote soil carbon sequestration in the grasslands of northern China (He et al. 2012). Dong et al. (2012) also reported a similar conclusion.

The relationships of the main environmental factors with the vegetation characteristics

The CA was used as an approach to screen out critical environmental factors associated with vegetation characteristics (Table 1). Precipitation is a key environmental factor in determining ecosystem structure and function (Saco et al. 2006), especially in grasslands and other water-limited regions, whereas soil nutrients control the distribution of plants (van Wijk et al. 2003; Zaller 2007). Zhou et al. (2009) found that BGB and soil carbon content remain relatively constant along the precipitation gradient. Our results also reveal significant relationships between precipitation and AGB, BGB, litterfall, and coverage in all management practices. Litterfall and coverage were strongly shaped by precipitation at the 0.05 level.
In fencing management, precipitation was positively correlated with AGB, BGB, and coverage, which was in agreement with other reports (Zhou et al. 2009). In grazing management, litterfall was negatively correlated with precipitation, which could be partly attributed to the poor living conditions of soil organisms in compacted soils and a significant reduction in litter (Xie and Wittig 2004). In savannahs, vegetation is also constrained by disturbance and limiting resources (Wang et al. 2012). Soil elements, especially TP, AP, and TN, often limit plant growth in natural ecosystems because of their central function in the photosynthetic apparatus and high mobility in the soil system (Bowman et al. 1993). In our study, the relatively low soil mineralization rates and low nutrient availability likely resulted in the relatively low litterfall in semi-arid environments of temperate grasslands in the Hulunbuir region.

The result was in agreement with previous findings that soil nutrient is a key constraint of vegetation biomes in grasslands (Sun et al. 2013a). Precipitation is related to MNDVI (Yearly maximum of Normalized Difference Vegetation Index), and the positive correlations are manifested in a linear manner. In arid and semi-arid region grasslands (Sun et al. 2013b), precipitation has a positive action in coverage related to grazing management. However, the mechanism of vegetation distribution with environmental factors in the Hulunbuir grasslands was explored.

Prediction of vegetation characteristics distribution with major environmental factors at the landscape scale

We predicted changes in vegetation characteristics correlated with the major environmental factors in the entirety of the grasslands by GAM analysis. The results indicated that precipitation was an important factor in shaping ecosystem functions, as reflected in litterfall and coverage in grassland ecosystems (Zhou et al. 2009). Our result was in accordance with the optimal partitioning hypothesis, which declares that plants respond to variations in environmental conditions by allocating biomass among various organs to capture nutrients, water, and light for maximizing their growth rate (Bloom et al. 1985). Plants generally allocate more biomass to shoots in high-nutrient or high-moisture environments, and shift more biomass to roots in low-nutrient or low-moisture conditions 
(McConnaughay and Coleman 1999). At the landscape scale, for different grassland management practices there were predicted different changed trends of vegetation characteristics aligned with critical environmental factors. Some predicted results contradicted traditional knowledge, thus necessitating further research.

\section{Conclusions}

The relationships between environmental factors and vegetation characteristics across 23 sites were analyzed, and we compared the effects of different management practices on the vegetation traits. The results indicated that fencing and mowing practices, which can improve vegetation traits, and increase grassland carbon sink, should be continued to promote the Hulunbuir grasslands, rather than grazing management. Thus, appropriate reforms concerning the proper utilize the grassland (e.g. mowing and fencing) is necessary to ensure sustainability of the grassland ecological system, and what is more, the effects of the ecological project in the sustainable development of the temperate grasslands in the Hulunbuir region should be gradually explored.

Acknowledgments This study was conducted under the auspices of the Strategic Priority Research Program of the Chinese Academy of Sciences (No. XDA05060100). We thank the Institute of Environmental Science of Hulun Buir for assistance in the field investigation. We are grateful to the anonymous reviewers for their constructive comments on the paper.

\section{References}

Bao SD (2000) Soil chemical analysis of agriculture. Chinese Agriculture Press, Beijing

Bloom AJ, Chapin FS, Mooney HA (1985) Resource limitation in plants-an economic analogy. Annu Rev Ecol Syst 16:363-392

Bowman WD, Theodose TA, Schardt JC, Conant RT (1993) Constraints of nutrient availability on primary production in 2 alpine tundra communities. Ecology 74(7):2085-2097

Burke IC, Lauenroth WK, Riggle R, Brannen P, Madigan B, Beard S (1999) Spatial variability of soil properties in the shortgrass steppe: the relative importance of topography, grazing, microsite, and plant species in controlling spatial patterns. Ecosystems 2(5):422-438

Dong QM, Zhao XQ, Wu GL, Shi JJ, Wang YL, Sheng L (2012) Response of soil properties to yak grazing intensity in a
Kobresia parva-meadow on the Qinghai-Tibetan Plateau, China. J Soil Sci Plant Nut 12(3):535-546

Geng Y, Wang YH, Yang K, Wang S, Zeng H, Baumann F, Kuehn P, Scholten T, He JS (2012) Soil respiration in Tibetan alpine grasslands: belowground biomass and soil moisture, but not soil temperature, best explain the largescale patterns. Plos One 7(4)

He NP, Zhang YH, Dai JZ, Han XG, Baoyin TGT, Yu GR (2012) Land-use impact on soil carbon and nitrogen sequestration in typical steppe ecosystems, Inner Mongolia. J Geogr Sci 22(5):859-873

Hui DF, Jackson RB (2006) Geographical and interannual variability in biomass partitioning in grassland ecosystems: a synthesis of field data. New Phytol 169(1):85-93

Jackson RB, Canadell J, Ehleringer JR, Mooney HA, Sala OE, Schulze ED (1996) A global analysis of root distributions for terrestrial biomes. Oecologia 108(3):389-411

Li SY, Li XB, Fu N, Wang DD, Wang H, Long HL (2007) An analysis on the degradation pattern of the steppe grassland on different slope in north China. Igarss: 2007 IEEE International Geoscience and Remote Sensing Symposium, Vols 1-12:3433-3436

Li XJ, Zhang XZ, Wu JS, Shen ZX, Zhang YJ, Xu XL, Fan YZ, Zhao YP, Yan W (2011) Root biomass distribution in alpine ecosystems of the northern Tibetan Plateau. Environ Earth Sci 64(7):1911-1919

Liu ZF, Liu GH, Fu BJ, Zheng XX (2008) Relationship between plant species diversity and soil microbial functional diversity along a longitudinal gradient in temperate grasslands of Hulunbeir, Inner Mongolia, China. Ecol Res 23(3):511-518

Liu ZF, Fu BJ, Zheng XX, Liu GH (2010) Plant biomass, soil water content and soil $\mathrm{N}: \mathrm{P}$ ratio regulating soil microbial functional diversity in a temperate steppe: a regional scale study. Soil Biol Biochem 42(3):445-450

Luo GP, Han QF, Zhou DC, Li L, Chen X, Li Y, Hu YK, Li BL (2012) Moderate grazing can promote above ground primary production of grassland under water stress. Ecol Complex 11:126-136

McConnaughay KDM, Coleman JS (1999) Biomass allocation in plants: ontogeny or optimality? A test along three resource gradients. Ecology 80(8):2581-2593

Medina-Roldan E, Paz-Ferreiro J, Bardgett RD (2012) Grazing exclusion affects soil and plant communities, but has no impact on soil carbon storage in an upland grassland. Agric Ecosyst Environ 149:118-123

Mofidi M, Jafari M, Tavili A, Rashtbari M, Alijanpour A (2013) Grazing exclusion effect on soil and vegetation properties in Imam Kandi Rangelands, Iran. Arid Land Res Manag 27(1):32-40

Paz-Ferreiro J, Medina-Roldan E, Ostle NJ, McNamara NP, Bardgett RD (2012) Grazing increases the temperature sensitivity of soil organic matter decomposition in a temperate grassland. Environ Res Lett 7(1)

R Development Core Team (2011) R: a language and environment for statistical computing. R Foundation for Statistical Computing, Vienna

Redmann RE, Romo JT, Pylypec B, Driver EA (1993) Impacts of burning on primary productivity of Festuca and StipaAgropyron grasslands in Central Saskatchewan. Am Midl Nat 130(2):262-273 
Saco PM, Willgoose GR, Hancock GR (2006) Spatial organization of soil depths using a landform evolution model. J Geophys Res-Earth 111(F2)

Schulze ED, Mooney HA (1993) Ecosystem function of biodiversity-a summary. Ecol Stud Ann 99:497-510

Scurlock JMO, Johnson K, Olson RJ (2002) Estimating net primary productivity from grassland biomass dynamics measurements. Global Change Biol 8(8):736-753

Sun DS, Wesche K, Chen DD, Zhang SH, Wu GL, Du GZ, Comerford NB (2011) Grazing depresses soil carbon storage through changing plant biomass and composition in a Tibetan alpine meadow. Plant Soil Environ 57(6):271-278

Sun J, Cheng GW, Li WP (2013a) Meta-analysis of relationships between environmental factors and aboveground biomass in the alpine grassland on the Tibetan Plateau. Biogeosciences 10(3):1707-1715

Sun J, Cheng GW, Li WP, Sha YK, Yang YC (2013b) On the variation of ndvi with the principal climatic elements in the Tibetan Plateau. Remote Sens-Basel 5(4):1894-1911

van Wijk MT, Williams M, Gough L, Hobbie SE, Shaver GR (2003) Luxury consumption of soil nutrients: a possible competitive strategy in above-ground and below-ground biomass allocation and root morphology for slow-growing arctic vegetation? J Ecol 91(4):664-676

Waldron S, Brown C, Longworth J (2010) Grassland degradation and livelihoods in China's western pastoral region A framework for understanding and refining China's recent policy responses. China Agric Econ Rev 2(3):298-320

Wang LX, Katjiua M, D'Odorico P, Okin GS (2012) The interactive nutrient and water effects on vegetation biomass at two African savannah sites with different mean annual precipitation. Afr J Ecol 50(4):446-454

Weiss N, Zucchi H, Hochkirch A (2013) The effects of grassland management and aspect on Orthoptera diversity and abundance: site conditions are as important as management. Biodivers Conserv 22(10):2167-2178
Whitford WG, Steinberger Y (2012) Effects of seasonal grazing, drought, fire, and carbon enrichment on soil microarthropods in a desert grassland. J Arid Environ 83:10-14

Wu GL, Du GZ, Liu ZH, Thirgood S (2009) Effect of fencing and grazing on a Kobresia-dominated meadow in the Qinghai-Tibetan Plateau. Plant Soil 319(1-2):115-126

Wu GL, Liu ZH, Zhang L, Chen JM, Hu TM (2010) Long-term fencing improved soil properties and soil organic carbon storage in an alpine swamp meadow of western China. Plant Soil 332(1-2):331-337

Xie YZ, Wittig R (2004) The impact of grazing intensity on soil characteristics of Stipa grandis and Stipa bungeana steppe in northern China (autonomous region of Ningxia). Acta Oecol 25(3):197-204

Yang YH, Fang JY, Ji CJ, Han WX (2009) Above- and belowground biomass allocation in Tibetan grasslands. J Veg Sci 20(1):177-184

Yang XH, Guo XL, Fitzsimmons M (2012) Assessing light to moderate grazing effects on grassland production using satellite imagery. Int J Remote Sens 33(16):5087-5104

Zaller JG (2007) Effect of patchy distribution of soil nutrients on root morphology and biomass allocation of selected grassland species: experimental approach. Pol J Ecol 55(4):731-747

Zheng XX, Liu GH, Fu BJ, Jin TT, Liu ZF (2010) Effects of biodiversity and plant community composition on productivity in semiarid grasslands of Hulunbeir, Inner Mongolia, China. Ann Ny Acad Sci 1195(S1):E52-E64

Zheng SX, Ren HY, Li WH, Lan ZC (2012) Scale-dependent effects of grazing on plant $\mathrm{C}$ : $\mathrm{N}$ : $\mathrm{P}$ stoichiometry and linkages to ecosystem functioning in the Inner Mongolia Grassland. Plos One 7(12)

Zhou XH, Talley M, Luo YQ (2009) Biomass, litter, and soil respiration along a precipitation gradient in Southern Great Plains, USA. Ecosystems 12(8):1369-1380 